\title{
Fibrosis Assessment
}

National Cancer Institute

\section{Source}

National Cancer Institute. Fibrosis Assessment. NCI Thesaurus. Code C127765.

An evaluation of the presence or degree of fibrosis present in a sample. 